\title{
DESEMPENHO FISIOLÓGICO DE SEMENTES DE FEIJÃO COLHIDAS EM DIFERENTES PERÍODOS DO DESENVOLVIMENTO
}

\author{
Physiological performance of bean (Phaseolus vulgaris L.) seeds \\ harvested in different developmental periods
}

\author{
Frederico José Evangelista Botelho ${ }^{1}$, Renato Mendes Guimarães², João Almir Oliveira², \\ José Renato Emiliorelli Evangelista ${ }^{3}$, Tiago de Aguiar eloi ${ }^{4}$, Danille Pereira Baliza ${ }^{2}$
}

\begin{abstract}
RESUMO
Na cultura do feijão (Phaseolus vulgaris L.), a época adequada de colheita para produção de sementes de alta qualidade é de suma importância. No presente trabalho objetivou-se determinar a época ideal de colheita para a obtenção de sementes com maior qualidade e produtividade. Para a instalação do campo experimental foram utilizadas sementes de feijão de duas cultivares (BRS Majestoso e BRS Horizonte). A colheita foi realizada manualmente, aos 70, 80, 90 e 100 dias após a emergência (DAE). Após a colheita foi feita a determinação do teor de água das sementes, e então as plantas foram secas ao sol, debulhadas manualmente e as sementes pesadas para verificação da produtividade. Em seguida, as sementes foram separadas ou não em quatro 4 classes de tamanho, sendo $3 \mathrm{em}$ peneiras (14/64, 17/64 e 18/64). Utilizou-se o delineamento experimental em blocos ao acaso, em esquema fatorial, em faixa, com quatro repetições. A avaliação da qualidade das sementes foi realizada por meio dos testes de germinação, índice de velocidade de emergência (IVE) e condutividade elétrica. Concluiu-se que a colheita aos 90 DAE propicia maior produtividade e qualidade de sementes de feijão das cultivares avaliadas.
\end{abstract}

Termos para indexação: Época de colheita, tamanho, qualidade.

\begin{abstract}
In beans crop (Phaseolus vulgaris L.), the ideal time of harvest for high quality seeds yield is very important. The objective of the present work was to determine the ideal time of harvest to abtain seeds with higher quality and productivity. For field experiment, seeds of two cultivars of the Carioca group (BRS Majestoso and BRS Horizonte) were used. The sowing was done manually and each parcel had four 12-meter-long lines, with a space of $0.40 \mathrm{~m}$ between them. The harvest was done manually, at 70 , 80, 90 and 100 days after the emergency (DAE). After the harvest, seed water content was determined and then, the plants were drought in the sun, threshed and weighed for productivity verification. After that, seeds were separated in 4 classes according to size, 3 in bolters $(14 / 64,17 / 64$ and 18/64). The experimental design used was randomized blocks, in factorial scheme, in lays, with four replicates. The evaluation of the quality of the seeds was carried out through germination tests, emergency speed index (IVE) and electrical condutivity. As a conclusion, the 90 DAE harvest enables greater productivity and quality of the evaluated cultivar of bean seeds.
\end{abstract}

Index terms: Harvest time, size, quality.

(Recebido em 9 de outubro de 2009 e aprovado em 10 de março de 2010)

\section{INTRODUÇÃO}

A cultura do feijão (Phaseolus vulgaris L.), devido à importância dos grãos na alimentação humana, tem merecido grande destaque no cenário nacional e internacional, suprindo as necessidades dos consumidores como fonte básica de proteínas e calorias. O Brasil assume o posto de maior produtor mundial de feijão-comum (Companhia Nacional de AbastecimentoCONAB, 2008). Dependendo da região, o feijoeiro é cultivado praticamente durante o ano inteiro. No entanto, a taxa de utilização de sementes certificadas ainda é muito baixa, correspondendo a $13 \%$ na safra $2005 / 06$, o que é explicado pelo fato da grande maioria dos produtores ser de pequeno porte, além da grande diversidade de tipos de feijão cultivados em cada região do Brasil (Associação Brasileira de Sementes e Mudas-ABRASEM, 2006).

As sementes são responsáveis por grande parte do rendimento de uma lavoura, e os esforços por parte dos produtores para produção de sementes de alta qualidade representam uma base sólida para o sucesso da lavoura. Nesse aspecto, a classificação das sementes em lotes de diferentes tamanhos, além de uniformizar a operação de semeadura e, consequentemente, proporcionar melhor estande e rendimento da lavoura, torna eficiente também o

\footnotetext{
1Universidade Federal de Lavras/UFLA - Departamento de Agricultura/DAG - Cx. P. 37 - 37200-000 - Lavras, MG - fredericojeb@yahoo.com.br 2Universidade Federal de Lavras/UFLA - Departamento de Agricultura/DAG - Lavras, MG

${ }^{3}$ Msc Engenheiro Agrônomo - Monsanto Brasil - Rio Verde, GO

${ }^{4}$ Universidade Federal de Lavras/UFLA - Lavras, MG
} 
tratamento das sementes (Krzyzanowski et al., 1991; Carvalho \& Nakagawa, 2000). O tamanho da semente, em muitas espécies, é indicativo de sua qualidade fisiológica (Popinigis, 1985). As sementes maiores, normalmente, possuem embriões bem formados e com maiores quantidades de reservas (Carvalho \& Nakagawa, 2000), portanto em um mesmo lote, as sementes maiores, potencialmente apresentam maior poder germinativo e vigor que as sementes menores, embora existam controvérsias quanto aos benefícios da classificação por tamanho. Fantinatti-Linares (1999) trabalhando com sementes de feijão encontrou diferenças significativas quando comparou sementes com tamanhos diferentes. Segundo o mesmo autor, foi observado um melhor desempenho das sementes grandes quando essas foram comparadas com as de menor tamanho.

Outro fator de grande importância para a produção de sementes de qualidade é a época adequada de colheita das sementes de feijão, pois a porcentagem de sementes infectadas por micro-organismos ou atacadas por insetos aumenta, enquanto a germinação e o vigor diminuem à medida que se prolonga seu tempo de permanência no campo após a maturidade fisiológica, aguardando o momento de colheita (Rena \& Vieira, 1971). A maturidade fisiológica coincide com o momento em que cessa a transferência de matéria seca da planta para as sementes; nessa ocasião, o potencial fisiológico é elevado, senão máximo. Diante desse fato, seria extremamente natural a decisão de efetuar a colheita dos campos de produção de sementes quando a população de plantas atingisse a maturidade fisiológica. No entanto, existem muitas dificuldades em se definir o ponto exato de colheita, uma vez que, no ponto de maturidade fisiológica, a semente encontra-se com um grau de umidade elevado, e por outro lado, o atraso da colheita a partir desse ponto acarreta vários inconvenientes, determinados pela exposição relativamente prolongada das sementes a condições menos favoráveis do ambiente (Marcos Filho, 2005). Assim, o estabelecimento de um ponto ideal de referência para a colheita das lavouras de feijão destinadas à produção de sementes precisa ser determinado, considerando a produtividade, o tamanho e a qualidade das sementes e a interação entre esses fatores.

Nesta pesquisa, teve-se como objetivo determinar a época ideal de colheita para a obtenção de sementes com maior qualidade e produtividade, em dois cultivares de feijoeiro.

\section{MATERIAL E MÉTODOS}

O trabalho foi realizado no Campo Experimental, e no Laboratório de Análise de Sementes do Departamento de Agricultura (DAG) da Universidade Federal de Lavras
(UFLA), localizados no município de Lavras, na região sul de Minas Gerais, situado à latitude de $21^{\circ} 14^{\prime} \mathrm{S}$, longitude $40^{\circ} 17^{\prime} \mathrm{W}$ e altitude de $918,80 \mathrm{~m}$.

A semeadura foi realizada manualmente, em julho de 2007, utilizando sementes de feijão de duas cultivares do grupo Carioca (BRS Majestoso e BRS Horizonte). Cada parcela foi constituída de quatro linhas de $12 \mathrm{~m}$ de comprimento, espaçadas de $0,40 \mathrm{~m}$ entre linhas. A colheita foi realizada manualmente, aos 70, 80, 90 e 100 dias após a emergência. Após a colheita das plantas, as mesmas foram secadas ao sol até que as vagens estivessem em condições de serem debulhadas, com umidade de 10 a 13\%. Em seguida as sementes foram classificadas manualmente utilizando um conjunto de peneiras de orifícios redondos, colocadas justapostas em ordem decrescente de tamanho, nas seguintes dimensões de diâmetro: 18/64, 17/64 e 14/64 de polegadas, correspondendo a 7,15, 6,95 e 5,55 mm, respectivamente (Teste de Retenção em Peneiras). Foi mantida uma amostra de sementes sem classificação, que foi utilizada como testemunha. Foram realizados os seguintes testes para a avaliação da qualidade fisiológica das sementes. Determinação da umidade das sementes: $\mathrm{O}$ teor de água das sementes foi mensurado por meio do método padrão da estufa a $105^{\circ} \mathrm{C}$ por 24 horas, utilizandose duas repetições para cada amostra, segundo as Regras para Análise de Sementes (Brasil, 1992); Germinação: Utilizaram-se 200 sementes por tratamento, divididas em 4 repetições de 50, com duas subamostras de 25 sementes por repetição. As sementes foram semeadas em rolo de papel Germitest@, umedecido com água destilada na quantidade de 2,5 vezes o peso do papel seco e mantidas em $\mathrm{BOD}$ à temperatura de $25^{\circ} \mathrm{C}$, na presença de luz. As avaliações foram realizadas conforme as Regras para Análise de Sementes - RAS (Brasil, 1992), com contagem das plântulas normais no quinto dia, e os resultados foram expressos em porcentagem de plântulas normais; Índice de velocidade de emergência: A semeadura foi realizada em bandejas plásticas contendo como substrato solo + areia na proporção $2: 1$. Foram utilizadas quatro repetições de 50 sementes por tratamento. Após a semeadura, as bandejas foram umedecidas até atingirem $70 \%$ da capacidade de campo e em seguida mantidas em câmara de crescimento vegetal à temperatura de $25^{\circ} \mathrm{C}$, em regime alternado de luz e escuro (12 horas). A partir da emergência das primeiras plântulas foram realizadas avaliações diárias, computando-se o número de plântulas emergidas até a estabilização. Foram consideradas emergidas as plântulas que apresentavam os cotilédones para fora do solo. Os índices foram determinados segundo a fórmula proposta por Maguire (1962); Condutividade elétrica: Foram 
utilizadas quatro repetições de 50 sementes por tratamento, as quais foram pesadas e em seguida colocadas em copos plásticos descartáveis, com $75 \mathrm{~mL}$ de água deionizada. Após 24 horas de embebição a uma temperatura de $25^{\circ} \mathrm{C}$, a condutividade elétrica foi determinada com auxílio de um condutivímetro de massa. A leitura foi efetuada em ì $\mathrm{Sm}-1$ e os resultados expressos com base no peso da amostra (î $\mathrm{cm}^{-1} \mathrm{~g}^{-1}$ ), de acordo com o método descrito por Vieira (1994).

Para a determinação da produtividade foram tomadas as plantas da parcela útil $\left(14,4 \mathrm{~m}^{2}\right)$ que após secadas até o ponto de debulha, foram debulhadas, e as sementes pesadas para a verificação da produtividade. As massas obtidas foram corrigidas para $13 \%$ de umidade, e os resultados expressos em Kilogramas por hectares $\left(\mathrm{kg} \mathrm{ha}^{-1}\right)$;

O delineamento estatístico utilizado foi em blocos casualizados, em esquema fatorial 2x4x4 (Cultivares, Épocas de colheita e Tamanho das sementes) para os testes de Germinação, Índice de velocidade de emergência e Condutividade elétrica, em esquema fatorial $2 \times 4$ (Cultivares e Épocas de colheita) para Produtividade, e em esquema fatorial 2x4x3 (Cultivares, Épocas de colheita e Tamanho das sementes ) para o teste de Retenção em peneiras, ambos em faixas, avaliando nas parcelas as cultivares, e nas subparcelas as épocas de colheita e os tamanhos das sementes, com 4 repetições. As análises estatísticas foram realizadas utilizando-se o software Sisvar® (Ferreira, 2000) e as médias foram comparadas pelo teste de Scott-Knott para cultivares e tamanho de sementes, e pela análise de Regressão, para épocas de colheita.

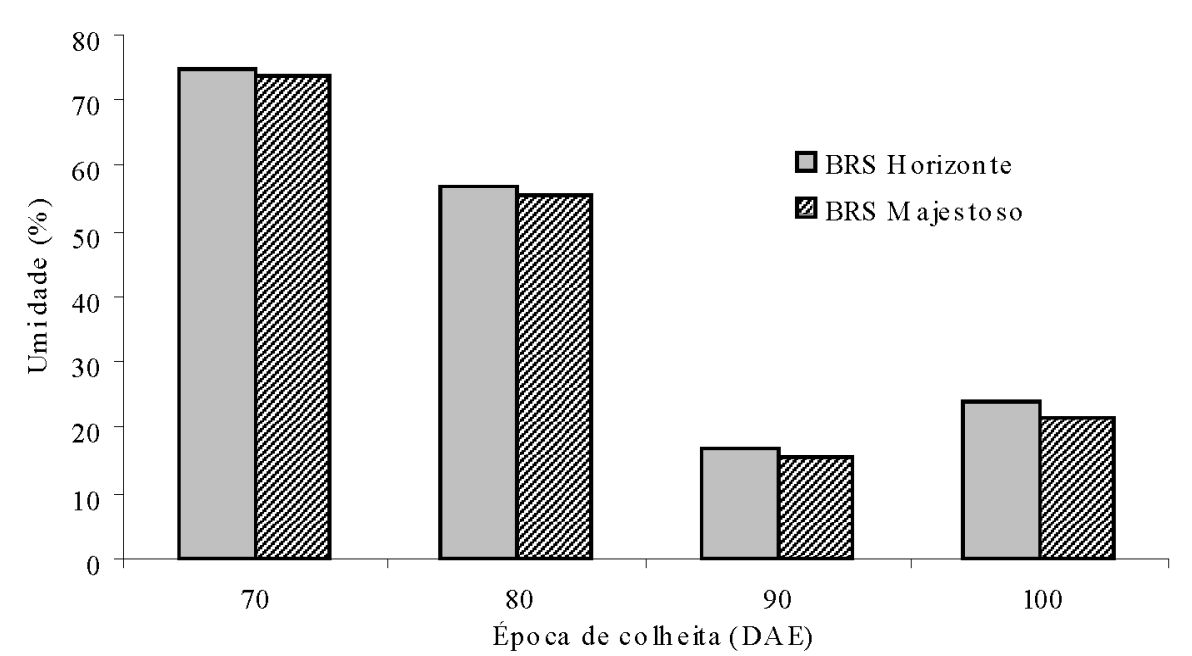

Figura 1 - Grau de umidade (\%) nas sementes de feijão, de duas cultivares, colhidas aos 70, 80, 90 e 100 dias após a emergência (DAE). UFLA, Lavras, MG, 2009.

Ciênc. agrotec., Lavras, v. 34, n. 4, p. 900-907, jul./ago., 2010

\section{RESULTADOS E DISCUSSÕES}

De acordo com a umidade de colheita das sementes, pode-se observar pela Figura 1, que, na primeira época de colheita das sementes, aos 70 dias após a emergência (DAE), as mesmas apresentaram altos teores de água, entre $70 \%$ e $80 \%$, e que a partir daí houve uma redução gradativa até 90 DAE (em média 16\%), ocorrendo um pequeno aumento aos 100 DAE (em média 23\%), em virtude do início do período chuvoso.

Conforme os resultados da análise de variância para a variável produtividade, a cultivar BRS Majestoso foi mais produtiva que a cultivar BRS Horizonte, sendo suas produtividades médias de 1782,52 e 1286,42 $\mathrm{Kg} \mathrm{ha}^{-1}$, respectivamente. As produtividades apresentaram uma tendência crescente até $90 \mathrm{DAE}$, em que observaram-se as maiores produtividades, e em seguida houve uma tendência de redução da produtividade das duas cultivares aos 100 DAE (Figura 2). Isso se deve ao início do período chuvoso na região e ao retardamento da colheita, os quais causaram uma perda expressiva de sementes pela abertura natural das vagens. Segundo Rocha et al. (1983) e Vieira et al. (1991) na região Sul de Minas Gerais, as temperaturas são baixas no inverno, e como o feijoeiro apresenta baixa germinação e crescimento nos meses mais frios dessa região, a semeadura precisa ser deslocada para o mês de julho ou mesmo início de agosto, como foi realizado nesse experimento. Esse retardamento, associado ao aumento do ciclo biológico das cultivares no período, resulta em coincidência da colheita com o início do período chuvoso na região, o que, além de comprometer a qualidade do produto, pode acarretar significativo decréscimo na produtividade. 
Silva \& Fonseca (1996) relataram que, além da redução da qualidade fisiológica da semente, a colheita realizada fora da época ideal pode afetar a produtividade e, quando o feijão é deixado por longo período no campo após a maturação, ocorreram perdas das sementes provocadas pela deiscência natural das vagens, ou pela operação de arranquio das plantas.

Para o teste de retenção em peneiras, pode-se observar na Figura 3 que, ao longo das épocas de colheita, houve uma redução na porcentagem de sementes retidas na peneira 14 , à medida em que há um aumento de sementes retidas nas peneiras 17 e 18 . Porém, a partir dos $90 \mathrm{DAE}$, as sementes retidas na peneira 18 , passam a representar um maior porcentual. Essa é uma tendência natural de ocorrência durante o desenvolvimento das sementes, uma vez que durante a formação das sementes há aumento do tamanho do embrião, assim como um acúmulo de reservas nas sementes.

Observa-se na Tabela 1 que a cultivar BRS Horizonte apresentou maior porcentagem de retenção na peneira 14 e, já a cultivar Majestoso o maior porcentual foi observado nas sementes maiores, retidas na peneira 18. Além disso, para a cultivar BRS Horizonte foi observado um maior porcentual de retenção de sementes menores, e já para a cultivar BRS Majestoso, embora também tenha sido observado uma maior porcentagem de retenção de sementes menores, a porcentagem de retenção de sementes maiores foi maior que na cultivar BRS Horizonte. Assim, pode-se observar ainda uma relação direta entre o tamanho das sementes e os resultados de produtividade para as

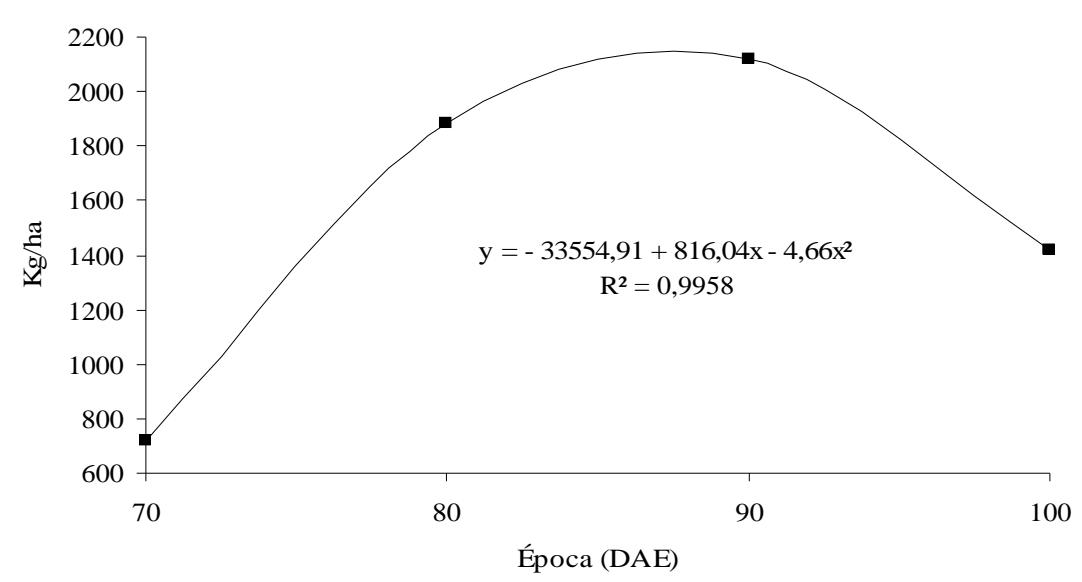

Figura 2 - Produtividade média $\left(\mathrm{Kg} \mathrm{ha}^{-1}\right)$ das cultivares de feijão, colhidas aos 70, 80, 90 e 100 dias após a emergência (DAE). UFLA, Lavras, MG, 2009.

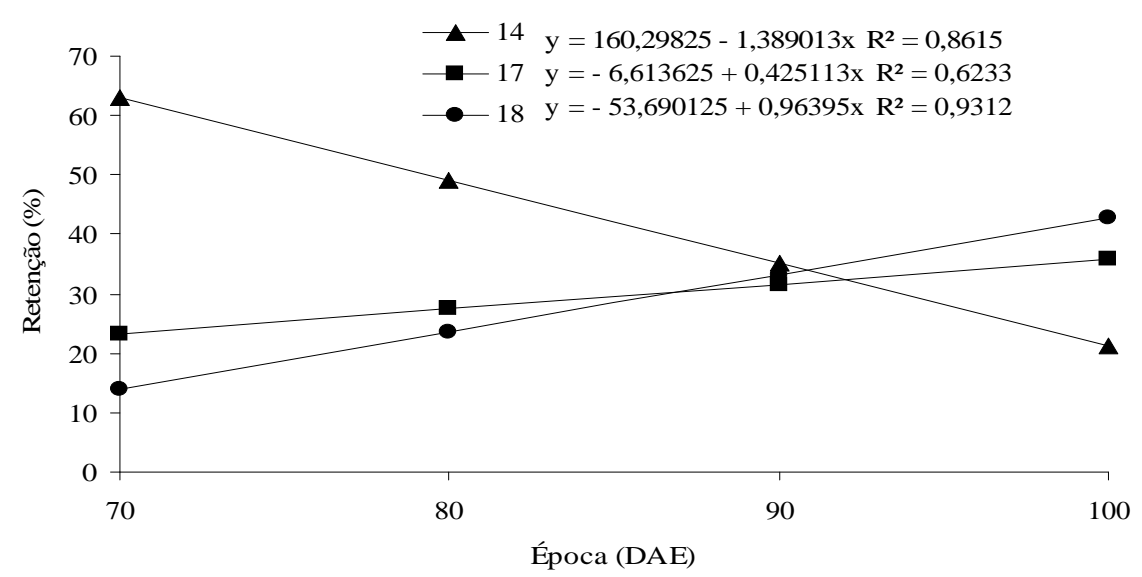

Figura 3 - Médias obtidas no teste de retenção em peneiras (\%) de sementes de feijão, colhidas aos 70, 80, 90 e 100 dias após a emergência (DAE). UFLA, Lavras, MG, 2009. 
duas cultivares, em que a cultivar BRS Majestoso com maiores porcentuais de sementes maiores, obteve maior produtividade.

Tabela 1 - Porcentagens médias obtidas no teste em retenção de peneiras (\%) de sementes de feijão, em função das cultivares BRS Horizonte e BRS Majestoso. UFLA, LAVRAS-MG, 2009.

\begin{tabular}{ccc}
\hline \multirow{2}{*}{ Tamanho } & \multicolumn{2}{c}{ Cultivar } \\
\cline { 2 - 3 } & BRS Horizonte & BRS Majestoso \\
\hline 14 & $46,8 \mathrm{Aa}$ & $37,7 \mathrm{Ba}$ \\
17 & $30,5 \mathrm{Ab}$ & $28,5 \mathrm{Ac}$ \\
18 & $22,7 \mathrm{Bc}$ & $33,8 \mathrm{Ab}$ \\
\hline
\end{tabular}

As médias seguidas de uma mesma letra maiúscula nas linhas e letras minúsculas nas colunas não diferem entre si, pelo teste de Scott-Knot, a 5\% de probabilidade.

No teste de germinação (Figura 4), pode-se observar um comportamento linear e crescente em função da época de colheita das sementes de feijão para a porcentagem de germinação, independente da cultivar.

A redução na qualidade das sementes observada no período de 90 DAE a 100 DAE, não foi detectada pelo teste de germinação. Esse teste geralmente superestima a germinação das sementes em relação à emergência em campo, já que inclui no resultado sementes com vigor insuficiente para emergir em condições subótimas ou desfavoráveis, como normalmente ocorre no campo (Delouche, 1975).

Já em função do tamanho das sementes, as sementes maiores, retidas nas peneiras 17 e 18 (Tabela 2), obtiveram porcentagens de germinação superiores às sementes menores, retidas na peneira $14 \mathrm{e}$ a testemunha. Foi observada uma relação direta entre o tamanho das sementes e a porcentagem de germinação. Pelos resultados apresentados na Tabela 3, pode-se constatar que sementes de peneiras inferiores a 17 podem influenciar negativamente a qualidade do lote , portanto a classificação por peneiras melhora a qualidade de lotes de sementes de feijão.

Tabela 2 - Médias obtidas no teste de germinação (\%) de sementes de feijão, em função da classificação por tamanhos. UFLA, LAVRAS-MG, 2009.

\begin{tabular}{lc}
\hline Tamanho & $\% \mathrm{G}$ \\
\hline Test & $93,1 \mathrm{~b}$ \\
14 & $91,9 \mathrm{~b}$ \\
17 & $96,1 \mathrm{a}$ \\
18 & $94,7 \mathrm{a}$ \\
\hline
\end{tabular}

As médias seguidas pela mesma letra não diferem entre si, pelo teste de Scott-Knot, a 5\% de probabilidade.

De acordo com Carvalho \& Nakagawa (2000), o tamanho da semente é um dos fatores que podem influenciar a germinação e o vigor das plântulas. As sementes maiores são as que foram mais bem nutridas durante seu desenvolvimento e que normalmente possuem embriões bem formados e com maiores quantidade de reservas, logo num mesmo lote, as sementes maiores, potencialmente, apresentam maior poder germinativo que as sementes menores.

Para o teste de índice de velocidade de emergência (Figura 5), a expressão do vigor das sementes seguiu ao

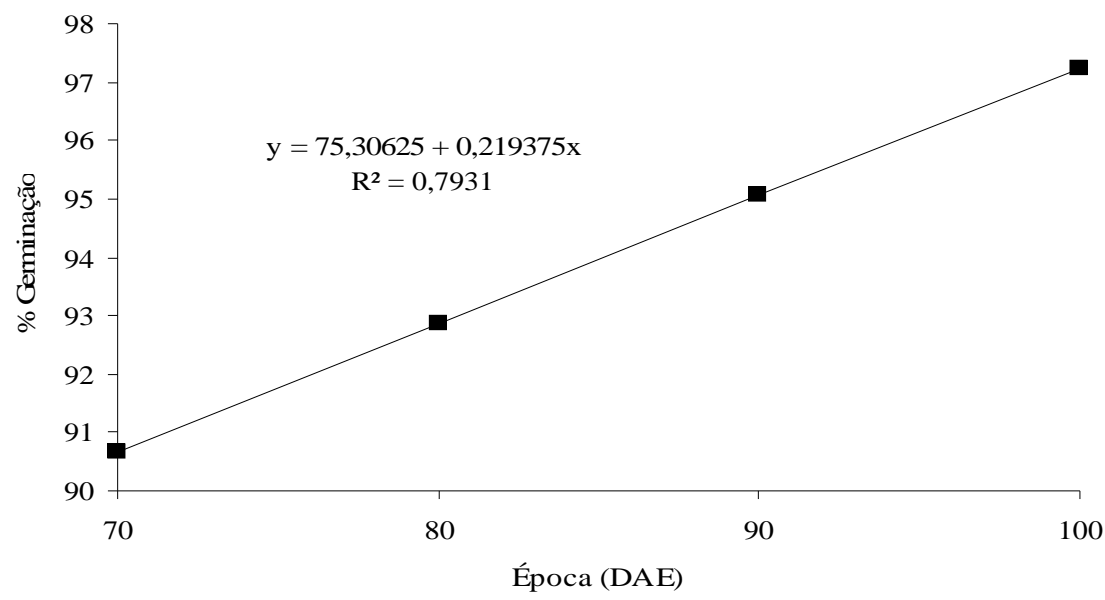

Figura 4 - Porcentagem média de germinação (\%) de sementes de feijão, colhidas aos 70, 80, 90 e 100 dias após a emergência (DAE). UFLA, Lavras, MG, 2009. 
longo do desenvolvimento um padrão que pode ser descrito em três fases. Na primeira fase, a partir dos 70 DAE houve uma tendência de redução. Depois, em uma segunda fase, a tendência foi de aumento no IVE até um ponto acima de 90 DAE. Essas tendências de redução na primeira fase e aumento na segunda no IVE podem ser explicadas pelo aumento e redução de ácido abscísico (ABA) endógeno. Em seguida, houve novamente uma tendência de queda no IVE, provocada pelo início do período chuvoso, o que provavelmente favoreceu o início do processo de deterioração, causando a queda no vigor.

Em algumas espécies, as sementes adquirem poder germinativo logo após a embriogênese, e em seguida passam por um período de dormência durante o desenvolvimento. Normalmente nesses casos, pode-se constatar um aumento no conteúdo de $\mathrm{ABA}$ ligado à baixa germinabilidade. Na fase seguinte do desenvolvimento, por redução relativa ou absoluta no conteúdo de ABA, as sementes voltam a expressar de forma crescente o poder germinativo, mas a germinação passa a ser impedida apenas pelo baixo conteúdo de água, naturalmente determinado nessa fase pela dessecação das sementes (Marcos Filho, 2005). De acordo com Rock \& Quatrano (1995), o ABA atua em diferentes eventos durante o desenvolvimento da semente, incluindo a inibição da germinação precoce e dormência. Segundo os mesmos autores, os níveis de ABA geralmente são elevados nos estágios iniciais do desenvolvimento e decrescem durante a maturação do embrião.

No teste de condutividade elétrica (Figura 6) observou-se uma resposta linear e decrescente em função das épocas de colheita para os diferentes tamanhos de

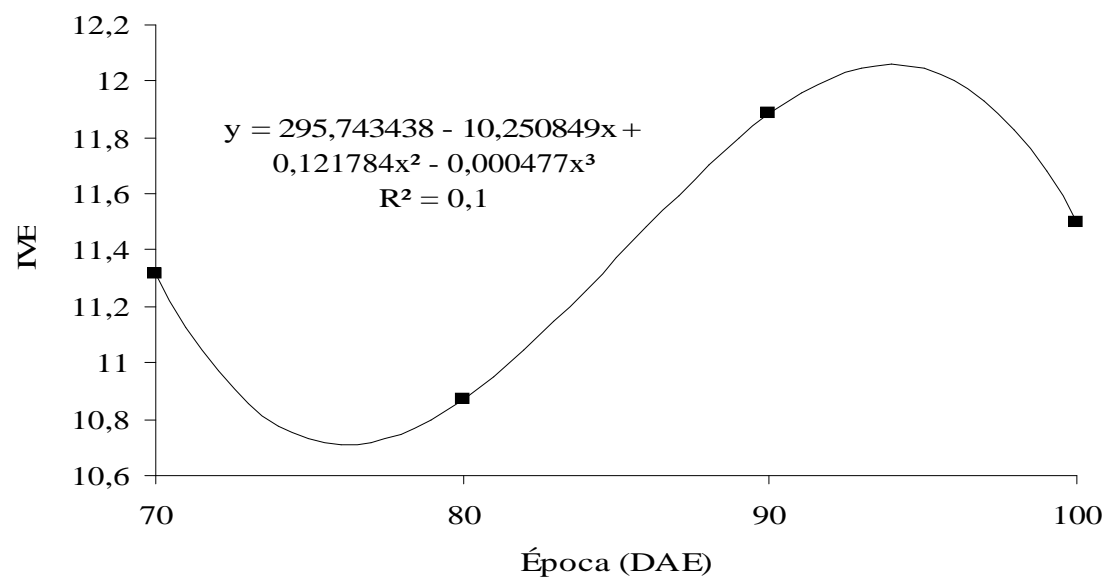

Figura 5 - Médias obtidas no teste de índice de velocidade de emergência (IVE) de sementes de feijão colhidas aos 70, 80, 90 e 100 dias após a emergência (DAE). UFLA, Lavras, MG, 2009.

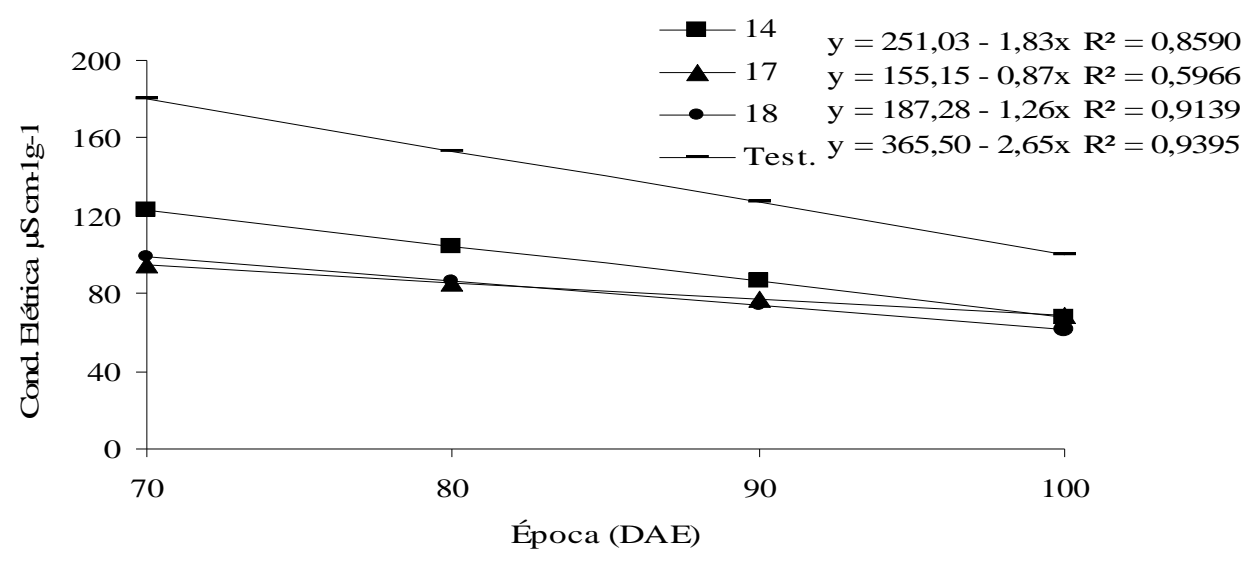

Figura 6 - Médias do teste de condutividade elétrica $\left(\mu \mathrm{sm}^{-1} \mathrm{~g}^{-1}\right)$ de sementes de feijão colhidas aos $70,80,90$ e 100 dias após a emergência (DAE). UFLA, Lavras, MG, 2009. 
sementes, existindo uma maior tendência de queda para a testemunha e as sementes retidas na peneira de 14 , respectivamente. Possivelmente, os altos valores de condutividade elétrica observados aos 70 e 80 DAE são devido à alta proporção de sementes ainda em fase de formação, as quais tiveram suas capacidades de reorganização das membranas celulares comprometidas no processo de embebição, o que favorece a liberação de maior quantidade de eletrólitos na solução. Já aos 90 e 100 DAE, esses valores tenderam a diminuir, uma vez que essas sementes já se encontravam em estádios finais do desenvolvimento, com suas membranas bem formadas. $\mathrm{O}$ estádio de desenvolvimento ou maturação da semente no momento da colheita é um dos fatores que pode também influenciar o resultado da condutividade elétrica. Desse modo, redução da condutividade elétrica, durante o processo de maturação das sementes, foi observada em ervilha (Bedford \& Matthews, 1976), em feijão-francês (Siddique \& Goodwin, 1985) e em milho (Vieira et al., 1995, 1999).

De acordo com a Tabela 3, observa-se que independente da época de colheita, para as sementes não classificadas (testemunha) pode-se observar menor vigor, quando comparamos com as sementes classificadas. Além disso, pode-se verificar que nas fases mais tardias do desenvolvimento, a condutividade elétrica do lixiviado das sementes assemelha-se independente dos tamanhos. Podese inferir, com base nessas observações que a integridade funcional das membranas celulares nas sementes é adquirida gradativamente durante o desenvolvimento e que essa integridade nas sementes menores acontece em fases mais tardias do desenvolvimento em relação às sementes de maior tamanho do mesmo lote. Martins et al. (1997) trabalhando com sementes de soja, verificaram maiores valores de condutividade elétrica em sementes pequenas em relação àqueles verificados em sementes médias e grandes.

Tabela 3 - Médias obtidas no teste de condutividade elétrica $\left(\mu \mathrm{S} \mathrm{cm}^{-1} \mathrm{~g}^{-1}\right)$ de sementes de feijão colhidas em quatro épocas de colheita, em função da classificação por tamanhos. UFLA, LAVRAS-MG, 2009.

\begin{tabular}{lrrrr}
\hline \multirow{2}{*}{ Tamanho } & \multicolumn{4}{c}{ Época de Colheita } \\
\cline { 2 - 5 } & \multicolumn{1}{c}{70} & \multicolumn{1}{c}{80} & 90 & 100 \\
\hline Test & $183,5 \mathrm{a}$ & $154,2 \mathrm{a}$ & $114,6 \mathrm{a}$ & $108,3 \mathrm{a}$ \\
14 & $117,3 \mathrm{~b}$ & $116,9 \mathrm{~b}$ & $76,8 \mathrm{~b}$ & $69,5 \mathrm{~b}$ \\
17 & $86,8 \mathrm{c}$ & $99,2 \mathrm{c}$ & $73,6 \mathrm{~b}$ & $66,5 \mathrm{~b}$ \\
18 & $96,0 \mathrm{c}$ & $93,0 \mathrm{c}$ & $69,1 \mathrm{~b}$ & $61,9 \mathrm{~b}$ \\
\hline
\end{tabular}

As médias seguidas pela mesma letra minúscula na coluna não diferem entre si, pelo teste de Scott-Knot, a 5\% de probabilidade.

\section{CONCLUSÕES}

Melhor qualidade das sementes e maior produtividade ocorre quando a colheita das Cultivares BRS Majestoso e BRS Horizonte é realizada aos 90 DAE.

A cultivar BRS Majestoso é mais produtiva, e apresenta-se com maior porcentagem de sementes retidas na peneira de maior diâmetro (18/64).

As sementes maiores, retidas nas peneiras 17/64 e $18 / 64$, são de melhor qualidade fisiológica, para as cultivares BRS Majestoso e BRS Horizonte.

$\mathrm{O}$ atraso na colheita, após o ponto ideal de colheita (90 DAE), proporciona queda na qualidade fisiológica das sementes e acarreta queda na produtividade devido à deiscência das vagens, para ambas as cultivares avaliadas.

\section{REFERÊNCIAS BIBLIOGRÁFICAS}

\section{ASSOCIAÇÃO BRASILEIRA DE SEMENTES E MUDAS. Anuário Abrasem 2006. Brasília, 2006. 86p.}

BEDFORD, L.V.; MATTHEWS, S. The effect of seed age at harvest on the germinability and quality of heat-dried seed peas. Seed Science and Technology, Zürich, v.4, n.2, p.275-286, 1976.

BRASIL. Ministério da Agricultura e Reforma Agrária. Regras para análise de sementes. Brasília: SNAD/CLAV, 1992. 365p.

CARVALHO, N.M.; NACAGAWA, J. Sementes: ciência tecnologia e produção. Jaboticabal: FUNEP, 2000. 588p.

\section{COMPANHIA NACIONAL DE ABASTECIMENTO.}

Acompanhamento da safra brasileira. Disponível em: $<\mathrm{http}$ / 'www.onab.gov.br/conabweb///>. Acesso em: $11 \mathrm{fev} .2008$.

DELOUCHE, J.C. Pesquisa em sementes no Brasil. Brasília: AGIPLAN, 1975. 47p.

FANTINATTI-LINARES, J.B. Qualidade de sementes de feijoeiro (Phaseolus vulgaris L.) de diversas densidades obtidas na mesa gravitracional. 1999. 50p. Dissertação (Mestrado)-Universidade Estadual de Campinas, Campinas, 1999.

FERREIRA, D.F. Análises estatísticas por meio do SISVAR para Windows versão 4.0. In: REUNIÃO ANUAL DA REGIÃO BRASILEIRA DA SOCIEDADE INTERNACIONAL DE BIOMETRIA, 45., 2000, São Carlos. Programa e Resumos... São Carlos: UFSCar, 2000. 
KRZYZANOWSKI, F.C.; FRANÇA-NETO, J.B.; COSTA, N.P. Efeito da classificação de sementes de soja por tamanho sobre sua qualidade e a precisão de semeadura. Revista Brasileira de Sementes, Brasília, v.13, n.1, p.5968, 1991.

MAGUIRE, J.D. Spped og germination aid in selection and evaluation for seedling and vigour. Crop Science, Madison, v.2, n.2, p.176-177, 1962.

MARCOS FILHO, J. Fisiologia de sementes de plantas cultivadas. Piracicaba: FEALQ, 2005. 495p.

MARTINS, C.O.A.; PADILHA, L.; FERREIRA, A.C.B.; MANTOVANI-ALVARENGA, M.; DIAS, D.C.F.S.

Influência da classificação por tamanho na germinação e no vigor de sementes de soja (Glycine max (L.) Merril). In: CONGRESSO BRASILEIRO DE SEMENTES, 10., 1997, Foz do Iguaçu. Informativo ABRATES, Curitiba, v.7, n.1/2, p.169, 1997.

POPINIGIS, F. Fisiologia da semente. 2.ed. Brasília: AGIPLAN, 1985. 289p.

RENA, A.B.; VIEIRA, C. Efeito da colheita, em diferentes estágios de maturação, na produção e na qualidade de feijão (Phaseolus vulgaris L.). Experientiae, Viçosa, v.11, n.6, p.239-257, 1971.

ROCHA, J.A.M.; VIEIRA, N.R. de; VIEIRA, E.H.N.; AIDAR, H. Efeito da antecipação da colheita sobre a produtividade e a qualidade da semente de feijão de terceira época de plantio. Goiânia: Embrapa-CNPAF, 1983. 15p. (EMBRAPACNPAF. Boletim de Pesquisa, 2).
ROCK, C.D.; QUATRANO, R.S. The role of hormones during seed development. In: DAVIES, P.J. Plant hormones. Dordrecht: Kluwer Academic, 1995. p.671697.

SIDDIQUE, M.A.; GOODWIN, P.B. Conductivity measurements on single seeds to predict the germinability of French beans. Seed Science and Technology, Zürich, v.13, n.3, p.643-652, 1985.

SILVA, J.G. da; FONSECA, J.R. da. Colheita. In: ARAUJO, R.S. et al. (Coords.). Cultura do feijoeiro comum no Brasil. Piracicaba: Potafos, 1996.

VIEIRA, C.; ARAÚJO, G.A. de A.; CHAGAS, J.M. Efeitos das datas de plantio sobre o feijão cultivado no outonoinverno. Pesquisa Agropecuária Brasileira, Brasília, v.26, n.6, p.863-873, jun. 1991.

VIEIRA, R.D. Teste de condutividade elétrica. In: VIEIRA, R.D.; CARVALHO, N.M. (Eds.). Testes de vigor em sementes. Jaboticabal: FUNEP, 1994. p.103-132.

VIEIRA, R.D.; MINOHARA, L.; CARVALHO, N.M.; BERGAMASCHI, M.C.M. Relationship of black layer and milk line development to maize seed maturity. Scientia Agricola, Piracicaba, v.52, n.1, p.142-147, 1995.

VIEIRA, R.D.; KRZYZANOWSKI, F.C. Teste de condutividade elétrica. In: KRZYZANOWSKI, F.C.; VIEIRA, R.D.; FRANÇA-NETO, J.B. (Eds.). Vigor de sementes: conceitos e testes. Londrina: ABRATES, 1999. p.4.1-4.26. 